\title{
Parametric design and Finite Element Analysis of metallic tanks transporting dangerous goods
}

\author{
Konstantinos Sykaras ${ }^{1}$, Michail Malikoutsakis ${ }^{1}$, Minas Loulas $^{1}$, and \\ Athanassios Mihailidis ${ }^{1, *}$ \\ ${ }^{1}$ Aristotle University of Thessaloniki, Faculty of Engineering, School of Mechanical Engineering, \\ Laboratory of Machine Elements \& Machine Design, 54124 Thessaloniki, Greece
}

\begin{abstract}
Metallic tanks are widely used for the transportation of dangerous goods. Manufacturers utilize standards in conjunction with European legislation concerning the international carriage (ADR and RID) to specify the minimum design and construction requirements. The analysis of the tank's attachment to the vehicle is not covered by analytical calculation methods, and only the Finite Element stress analysis can be used prior to manufacture. New ADR amendments demand that the certification authorities conduct stringent examinations that the manufacturer has the ability to perform high quality weldings. Applying the structural strength concept implemented in the International Institute of Welding (IIW) guidelines into the calculation is a protracted task. Aiming at speeding up the procedure, a parametric design and an efficient FE analysis is developed for a LGBF tank. Utilizing parametric design offers sufficient overview of the whole structure, while a supplementary surface model is generated to reduce pre-processing time. The tank is subjected to prescribed load cases, while the meshing directives of the structural hot spot stress concept (SHSSC) according to the IIW recommendations are incorporated in the procedure, in order to assess both the static and fatigue strength of the weld details. Using a multi-compartment LGBF tank as a case study, it is shown that the proposed detailed and automated analysis succeeds in reducing the time and effort needed, as well as in allocating the critical spots, substantially increasing the calculation accuracy.
\end{abstract}

\section{Introduction}

The European Agreement concerning the International Carriage of Dangerous Goods by Road (ADR) [1] is a United Nations treaty that governs the transnational transport of hazardous materials for more than 60 years. The Regulation regarding the International Carriage of Dangerous Goods by Rail (RID) [2] was modified 20 years ago by the protocol of the Intergovernmental Organisation for International Carriage by Rail. These legislations in conjunction with European Standards EN 13094:2015 [3] and EN 14025:2013 [4] cover the minimum requirements for the design, construction, equipment and inspections of fixed tanks, demountable tanks and tank-containers, with shells made of metallic materials.

*Corresponding author: amih@auth.gr 
National certification authorities need a technical report filed upon type approval applications of tanks. Along with the tank's compliance of the design and construction to the corresponding standards, the conformation to national laws and international agreements, the design engineers must submit complementary calculations of the overall structure. The tank's attachment to the vehicle is not covered by the basic analytical calculations according to [3], and three individual procedures are recommended for the verification of its design. The estimation of the stress field around the tank supports or attachments and consequently in the welded regions can be based on the actual tank-vehicle arrangement testing and measurements or on numerical simulations. A suitable tool is the Finite Element stress analysis, which shall be used prior to the tank's fabrication.

It should be emphasized that the verification of the load carrying capacity of weldments is of such significance that the European legislation introduced new enhancements. From 2017 onwards, it is demanded that the certification authorities conduct stringent examinations to check if the welding operations of the manufacturer meet or exceed the prescribed quality standards in addition to the already in force time-consuming integrity inspections to all weld beads of a built tank.

Calculation of the welds, especially for the tank attachments, can be carried out by applying the International Institute of Welding (IIW) structural strength concepts in a FE analysis [5]. These guidelines allow for durability assessment of welded structural details through linear static analysis of the structure following specific directives over the meshing practices. For thin sheet welded structures, the Structural Hot Spot Stress Concept (SHSSC) is applied on a shell element mesh.

The employment of this concept requires time-consuming work for embedding the required principles within the FE pre-processing. In the direction of speeding up the procedure and enhance its accuracy, a parametric design is developed. Managing and working with numerical parameters in a CAD software offers sufficient overview of the whole structure with minimal effort, while a supplementary model is used to create the offset surfaces of the whole tank assembly and apply those meshing directives in order to reduce the pre-processing time.

The aim of this study is to demonstrate a workflow that on one hand follows the legislation's articles in conjunction with the structural strength concept implemented in the IIW guidelines into the calculation of tanks, and on the other hand significantly reduces the required engineering effort and time by incorporating parametric design. An already in service multi-compartment aluminium alloy LGBF fixed tank is used as example. The analysis of the specific case study has successfully allocated the failure critical locations, substantially increasing the calculation accuracy of tanks transporting dangerous goods, assess its life expectancy and monitor the failure-critical weld points.

\section{Model Description}

\subsection{Tanks for transport of dangerous goods}

The tank under investigation is of type LGBF, used for the carriage of fuel products (class 3 substances as described in the ADR) and has modified-oval cross-section. The shell is divided into 7 compartments with a total capacity of 28092 litres.

According to legislation and standards, the tank is to be subjected to specific load cases for both analytical and numerical analyses. They originate from three loading scenarios: i) operational requirements from extreme driving scenarios (fig 1a), called according to [3] "dynamic conditions", ii) test pressures (whole tank fig 1b.5 and compartment fig 1b.6), called "pressure conditions", and iii) partial vacuum conditions (fig 1b.7). 
In order to simulate the operational requirements, the whole structure must be designed to withstand the loads resulting from the following static load cases in combination with the working pressure: 1) twice the total weight in the direction of travel, 2) the total weight of the tank in the lateral direction, 3) the total weight of the tank vertically upwards and 4) twice the total weight vertically downwards.

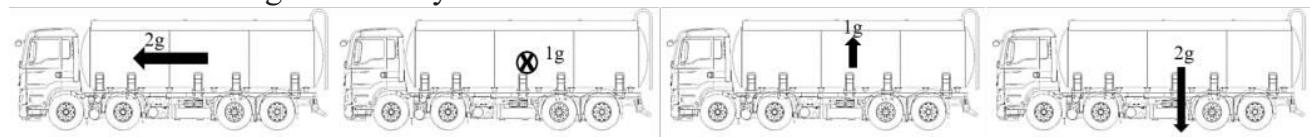

a. Static load for the dynamic conditions: 1) $2 \mathrm{~g}$ forwards, 2) $1 \mathrm{~g}$ side, 3) $1 \mathrm{~g}$ upwards and 4) $2 \mathrm{~g}$ downwards

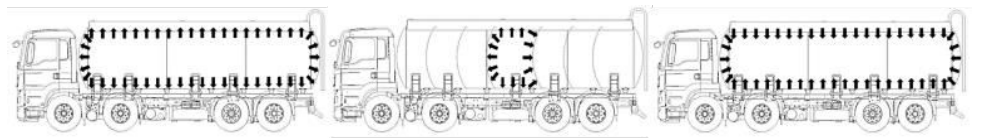

b. Pressure conditions: 5) tank test pressure, 6) compartment test pressure and 7) partial vacuum

Fig. 1. ADR and EN 13094 load configurations.

Under the above dynamic conditions, shells, their attachments and their structural equipment must withstand the forces and the working pressure. The forces are to be applied on the maximum design mass and their high value originates from the need to protect the structure from dangers, and the environment from the hazardous goods that need to be transported. The loads on the different directions simulate the extreme driving manoeuvres of braking from an excessive speed, an extreme turning, while the vertically upwards and downwards accelerations simulate potholes and rumble strips.

The pressure conditions cases are tested both on the whole tank and on each compartment separately. The pressure values derive from EN 13094 [3] specifications and depend on the tank technical characteristics, while the 0.03 bar underpressure is common for every tank transporting dangerous goods with a working pressure not exceeding 0.5 bar, to ensure the watertightness and structural adequacy of tanks.

\subsection{Parametric design}

The main idea is to start the design and analysis of a new tank based on a previously designed template. It includes all essential parameters to accurately describe the geometry of the tank. Moreover, it includes the data needed to create the FE shell mesh and to apply the SHSSC principle for the calculation of the welds as well. In the example shown, the parameter count reached 200. They are organized in three main groups: Geometry, Function and Analysis. Some examples are shown in fig $2 b$.

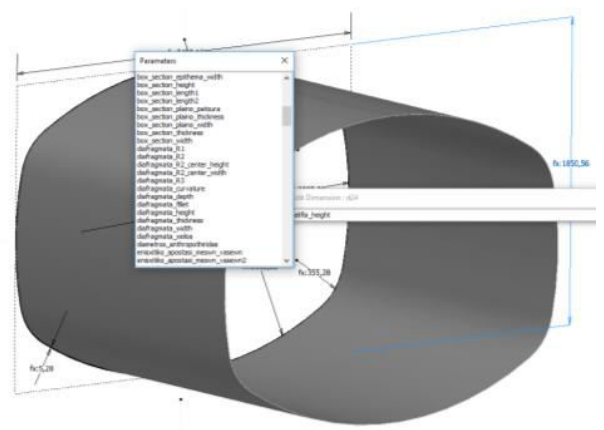

a. Selecting a parameter for the shell dimensions

\section{Size parameters (154 in total)}

1.1 Shell thickness

1.2 Front end curvature R2 $350 \mathrm{~mm}$

1.3 Partition 4 depth $280 \mathrm{~mm}$

2. Functional parameters (33 in total)

2.1 Distance attachment 1-2 $1000 \mathrm{~mm}$

2.2 Distance manhole 1-2 $900 \mathrm{~mm}$

3. Analysis parameters ( 3 in total)

3.1 Reference point $1 \quad 2.4 \mathrm{~mm}$

b. Parameter groups and examples

Fig. 2. Screenshots and parameter list of CAD model. 
They can be used to model new tanks with the most commonly used cross-sections. In addition, the coefficients of the offset distances utilized by the SHSSC were appended to create the offset reference point lines and speed up the pre-processing time of FE analysis.

\subsection{Weld assessment based on the Structural Hot Spot Stress Concept}

The directives of the Structural Hot Spot Stress Concept (SHSSC) described in IIW [6] recommendations will be used to assess both the static and fatigue strength of the critical weld details. The concept is valid for thin sheet structures and tanks could be considered as one of the most typical cases to apply this methodology. The calculated value of the structural stress $\sigma_{S}$ considers the stress concentration effects and depends on the dimensions and type of the weld detail, material and loading conditions.

Fatigue crack initiations are likely to be developed at weld toe areas, so the hot spot stresses must be allocated in these zone areas. In most cases, the maximum principal stresses result in the vicinity of these regions due to the notch created by the weld toe transition. The basic idea is to extrapolate the calculated stress values on predefined distances from the weld toe and assess them within appropriate Wöhler curves.

The hot spot stress $\sigma_{H S}$ for the case of fillet welds is calculated by Equation (1) which is a linear extrapolation of the nodal stresses at the two reference points as shown in the following figure 3 :

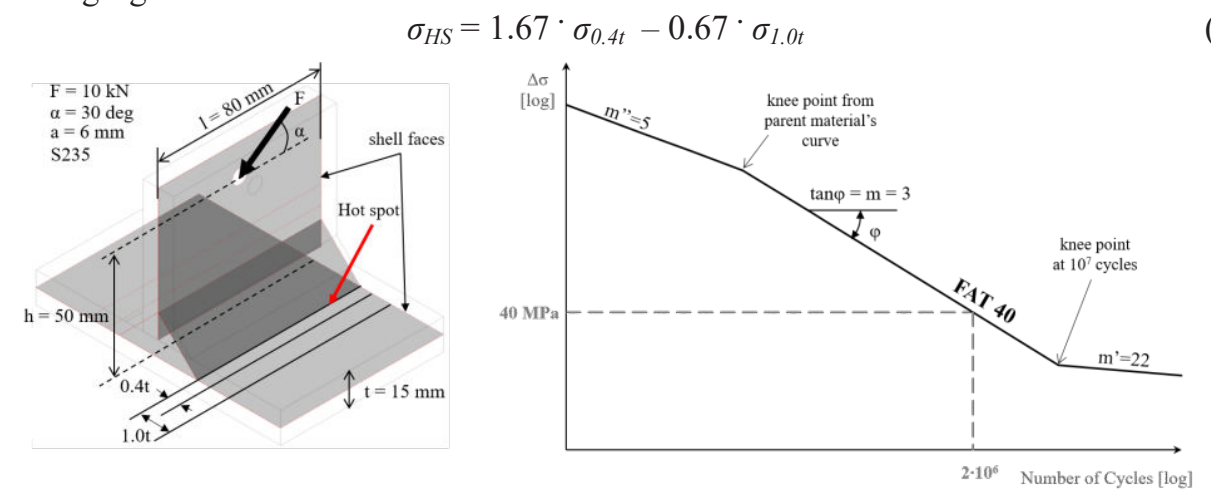

Fig. 3. Calculation of hot spot stresses according to SHSSC and a representation of a FAT40 curve.

The evaluated stress can be assessed in terms of durability of the corresponding structural detail, utilizing standardized fatigue resistance curves, which depend on the type of the weld detail, material properties and loading conditions. FAT curves allocate the fatigue life expectancy of the structural detail with a $97.7 \%$ probability of survival and stress ratio $R=\sigma_{\min } / \sigma_{\max }=0.5$. To define this curve a nominal slope $\mathrm{m}(\mathrm{m}=3$ for weld details under tension/compression and bending, $\mathrm{m}=5$ for torsion) with a given value of stress range at $2 \cdot 10^{6}$ cycles. Furthermore, the knee point is characterized using a slope of $\mathrm{m}^{\prime}=22$ at $10^{8}$ cycles, regardless of the loading conditions.

\subsection{FE Model}

In order to check the finite element modelling of the weldments, two different simulations were carried out, using the very simple example of two welded plates, as shown in fig. 3 and their results were compared to the traditional, well established, analytical calculation method [7]. 
The first approach was to simulate the weldment with an inclined shell face in contact with the two perpendicular shell faces that matched the middle surface of the solid. For the second approach, the inclined shell face was substituted with a seamline from the connector manager of the pre-processing software.

Utilizing the IIW guidelines, the hot spot stress $\sigma_{H S}$ was calculated $50.85 \mathrm{~N} / \mathrm{mm}^{2}$, which led to $2.13 \cdot 10^{7}$ cycles to failure. Following the second approach the same stress was found only $23.05 \mathrm{~N} / \mathrm{mm}^{2}$ resulting in $7.74 \cdot 10^{14}$ cycles to failure. In both approaches, the values are beyond the fatigue limit as they are greater than $10^{7}$. Following the traditional method, a safety factor $S=1.66$ was found, a value indicating endurance beyond the fatigue limit. Therefore, it was chosen to model the weldment with an inclined shell face following the first approach. Moreover, it is the safest choice to use in combination with the SHSSC.

The mesh on the tank has been generated in a uniform manner, using mostly quadratic shell elements (10 mm element length), while the instances tool of ANSA has been employed to accelerate the meshing process. The meshing of the welded areas conforms to the SHSS concept described in the IIW regulations. In the detail of figure $4 b$, the meshing in critical welded areas is depicted as.

For the load cases derived from the ADR and the EN 13094 documentation, in the dynamic conditions the tank is assumed to be completely (100\%) filled with water at an ambient temperature of $20^{\circ} \mathrm{C}$. To simulate the dynamic conditions a working pressure is applied, which is calculated according to the type of the transported substances (petroleum products) following the requirements of the European legislation. A distributed pressure normal to the surfaces of the tank (fig. 5), resulting from the inertial movement of the tank's substances, was selected in order to enhance the accuracy of the analysis.

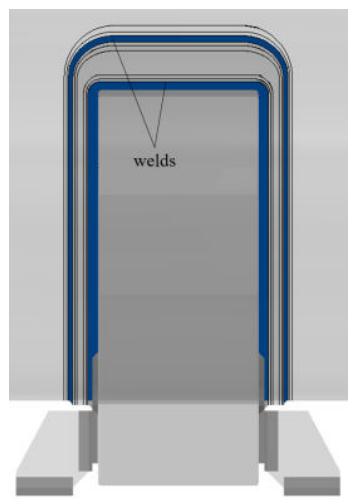

a. Offset distances

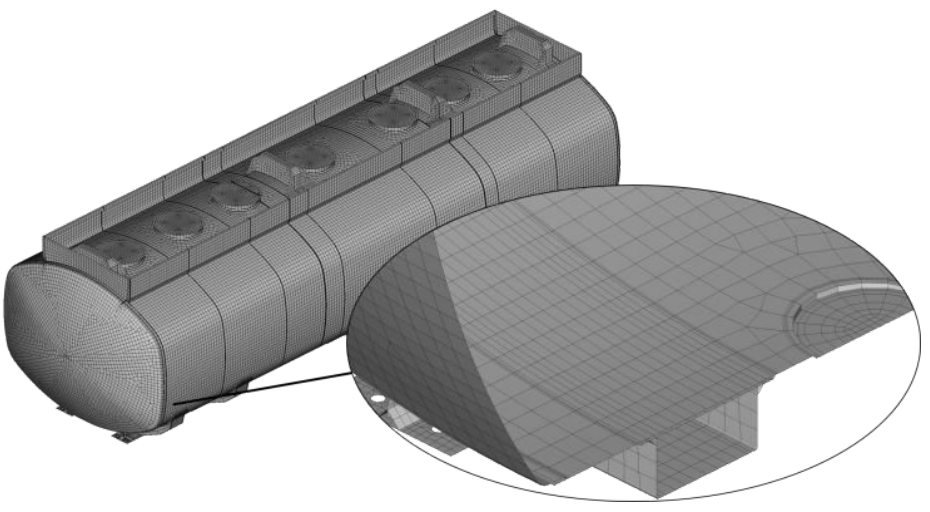

b. Attachment detail

Fig. 4. Tank Finite Element Model.

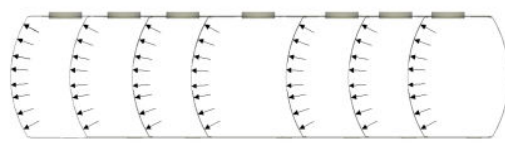

a. $2 \mathrm{~g}$ forwards

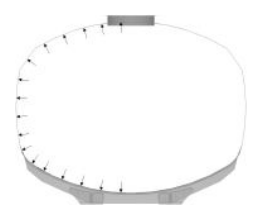

b. $1 \mathrm{~g}$ lateral

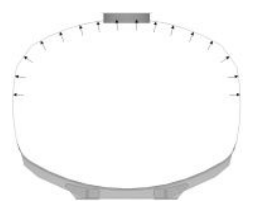

c. $1 \mathrm{~g}$ upwards

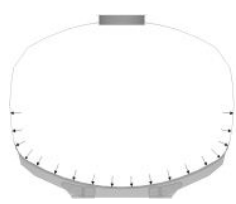

d. $2 \mathrm{~g}$ downwards

Fig. 5. Loading boundary conditions.

For both dynamic and pressure loading scenarios all the degrees of freedom of the support nodes were fixed, while the load application areas were alternated according to the respective load case. 
The 2D shell element model created, has been analysed using linear elastic analysis with the nominal sheet thicknesses. The metal selected by the tank manufacturers are the aluminium alloys derived from the EN 14286 [8], which also provided the material data and mechanical properties.

\section{Results}

The solution was obtained utilizing the Epilysis solver integrated into the ANSA [9] preprocessing environment, while the META [10] was employed to evaluate the results.

The failure critical locations were identified for each load case and are illustrated in Table 1. Those areas present stress maxima due to the respective overall loading or due to geometrical stress concentration.

Table 1. Failure critical locations and evaluation of calculated nodal values according to SHSSC.

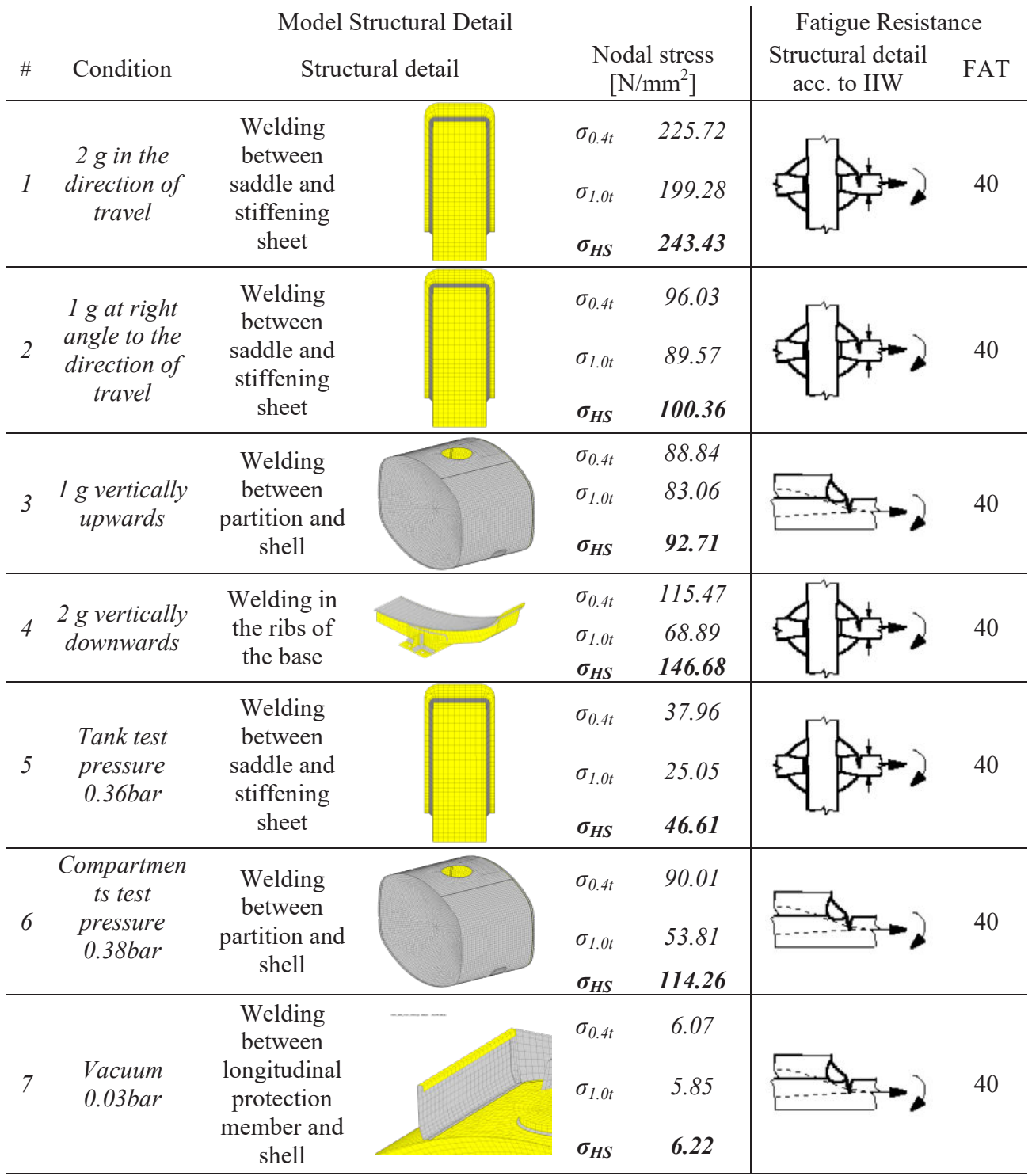


The resultant stresses in the shell are compared to the maximum allowable design stresses specified in the legislation in terms of confrontation. In the welded regions the results are assessed in terms of durability according to the IIW guidelines.

The FAT 40 curve depicted in figure 6 is laid against $\sigma_{H S}$ to allocate the fatigue life of the four respective weld details that exceed the maximum design stress (horizontal line of $93.75 \mathrm{~N} / \mathrm{mm}^{2}$ ) in the material of the tank indicated in the EN 13094. These exceeded stress values illustrate the importance of assessing the fatigue life expectancy of the structural details.

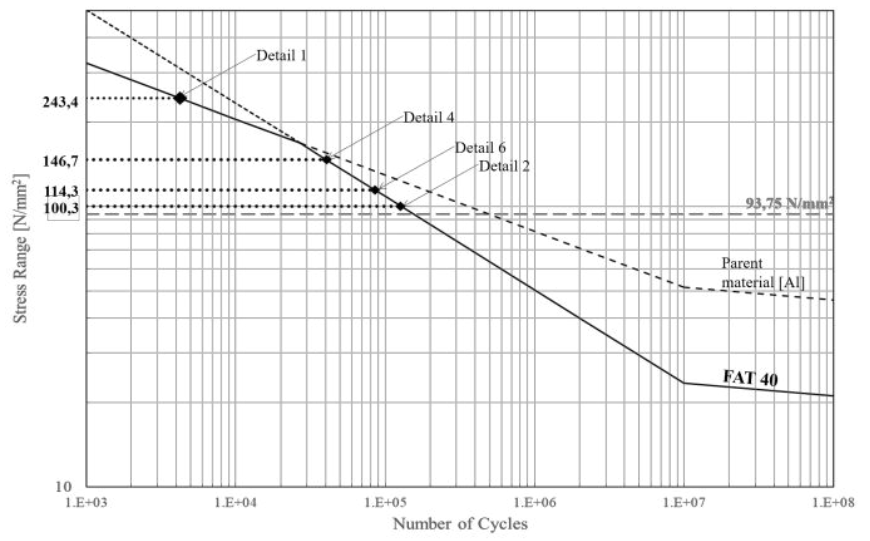

Fig. 6. Fatigue life expectancy of selected weld details (Table 1).

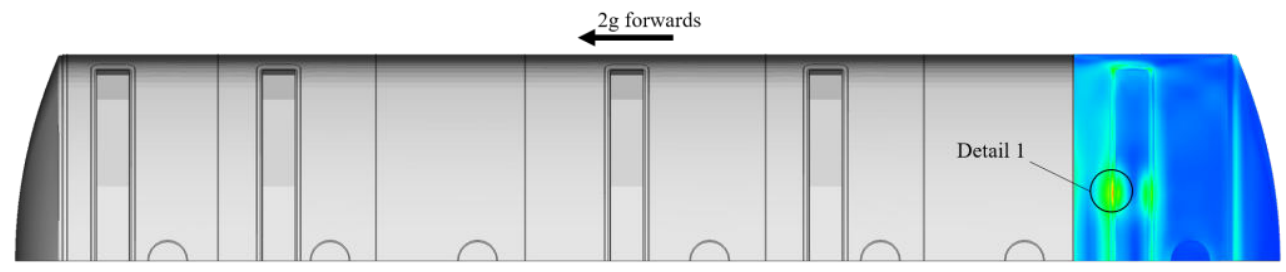

a. Detail 1 -Compartment 7, saddle 5, $2 \mathrm{~g}$ in the direction of travel

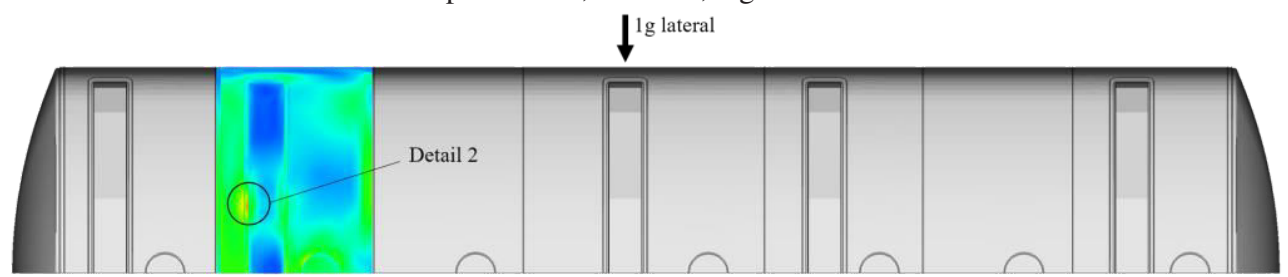

b. Detail 2 - Compartment 1 , saddle $1,1 \mathrm{~g}$ at right angle to the direction of travel

Fig. 7. Top view of details $1 \& 2$ (Table 1 ).

\section{Conclusions}

The procedure outlined and the parametric design of the multi-compartment LGBF tank presented, is a follow-up of previous work, aiming at automating the design and analysis of the tank, reducing the engineering effort while maintaining accuracy and legislation conformity. The principal of SHSSC described by IIW, has been incorporated in the parametric design of the tanks and reduced drastically the pre-processing time of $\mathrm{FE}$ analysis. 
Additionally, it was revealed that the highly stressed regions of a commercial multicompartment LGBF tank, are located in the area of the supports in most cases of the ADR load configurations.

The utilization of the Structural Hot Spot Stress Concept described in the IIW guideline assisted to quantify the failure locations along with their fatigue life expectancy. Dynamic tests of manufactured and in use road tanks according to the test programme described in the European Agreement would deliver a better estimation of the timespan at which the failure would occur.

Lastly but equally decisively, the adoption of the proposed directives over the meshing procedure offers a way of treating these structures under the operating legislation field in a uniform manner, produce comparable results and strengthen the assessment methods of the certification authorities.

The authors would like to thank BETA CAE Systems, for providing the ANSA, Epilysis and META software suites.

\section{References}

1. ADR, European Agreement concerning the International Carriage of Dangerous Goods by Road (ADR), Economic Commission for Europe, Committee on Inland Transport, United Nations, New York and Geneva (2017).

2. RID, Regulation concerning the International Carriage of Dangerous Goods by Rail (RID), Intergovernmental Organisation for International Carriage by Rail (OTIF), Berne (2017).

3. EN 13094, Tanks for the transport of dangerous goods Metallic tanks with a working pressure not exceeding 0,5 bar Design and construction, European Committee for Standardization, Brussels (2015).

4. EN 14025, Tanks for the transport of dangerous goods Metallic pressure tanks Design and construction, European Committee for Standardization, Brussels (2013).

5. G. Savaidis, M. Malikoutsakis, A. Savaidis, Int. J. Appl. Struct. Integ. Vol. 4 No. 3, pp. 383-395 (2013).

6. A. Hobbacher, IIW Document XIII-2151-07 / XV-1254-07 (2007).

7. G. Niemann, H. Winter, B.-R. Höhn, Maschinenelemente - Band 1: Konstruktion und Berechnung von Verbindungen, Lagern, Wellen, Springer-Verlag Berlin Heidelberg (2005).

8. EN 14286, Aluminium and aluminium alloys Weldable rolled products for tanks for the storage and transportation of dangerous goods, European Committee for Standardization, Brussels (2008).

9. BETA CAE Systems S.A., ANSA version 18.1.x User's Guide, BETA CAE Systems (2017).

10. BETA CAE Systems S.A., META version 18.1.x User's Guide, BETA CAE Systems (2017). 